\title{
EFFECT OF LIGHT EMITTING DIODE (LED) VERSUS HALOGEN PHOTO- POLYMERIZATION ON SHEAR BOND STRENGTH OF THREE TYPES OF RESIN COMPOSITES
}

\author{
Mona Abd Eltawab*, Amira Al Zogby**, Faten Kamel** and Dalia Abu El Magd**
}

\begin{abstract}
Objective: This study investigated the effect of light emitting diode (LED) and halogen (QTH) photopolymerization on shear bond strength of three types of resin composites.

Materials and methods: Sixty molars were selected and randomly assigned into 6 groups. The materials used were: Hybrid resin composite, nano-filled resin composite and silorane based resin composite. The analyzed resin composites were polymerized either by LED or halogen curing systems. After 24 hours storage in distilled water the specimen was submitted to push-out shear bond strength testing using a universal testing machine at cross head speed of $0.5 \mathrm{~mm} / \mathrm{min}$. one debonded representative specimen of each tested group was examined using an environmental scanning electron microscope to determine the mode of failure.
\end{abstract}

Results: All the specimens cured by LED demonstrated higher shear bond strength than those cured by QTH. There was no statistically significant difference between the two light curing units (LCUs) except for nano-filled resin composite that showed a significant difference. Silorane based resin composite groups were statistically significant higher than nano-filled and hybrid resin composites groups. While nano-filled resin composites was statistically non-significant higher than hybrid resin composite groups.

Conclusions: (1) The light emitting diode is effective as halogen curing light to obtain resincomposite with shear bond strength of no significant difference. (2) The silorane-based resin-composite restorative material is promising material regarding bonding efficiency to dentin.

Recommendation: It is advised to cure nano-filled resin composite with light emitting diode (LED) to obtain higher shear bond strength to dentin.

\section{INTRODUCTION}

For reducing polymerization shrinkage and improving mechanical properties of resin composite, nano-filler particles have been introduced in the last years, which allow for a significant increase in filler volume. For further reduction of polymerization shrinkage, a special group of dental composite

\footnotetext{
* Post Graduate Student in Operative Dentistry, Cairo University

** Professor of Operative Dentistry, Cairo University
} 
materials has been developed under the name siloranes, which derives from their major chemical building blocks siloxanes and oxiranes. These materials polymerize by cationic ring-opening polymerization, which partially compensates volume shrinkage during polymerization (Hahnel et al, 2010).

The majority of light-activated resin-composites and dentin bonding agents (DBAs) contain camphorquinone as the main photo-initiator (Kim et al, 2005). So light-curing units (LCUs) must be able to bring enough energy to achieve the wavelength of the resin's photo-initiator to photoactivate (Nicoló et al, 2010 ).

Polymerization of resin composite is initiated when photoinitiators are activated by light. The available curing units, Halogen based (QTH), light emitting diode (LED), plasma arc or laser technology have different light intensities \& light sources with energy levels range from 300 to more than $1,000 \mathrm{~mW} / \mathrm{cm}^{2}$ (Journal of ADA, 2002).

Testing the bond strength of a given system is of a vital importance to evaluate the ability of this system to withstand the stresses generated by composite materials during polymerization and also during functioning in the oral environment with its thermal and mechanical fluctuations (Fahmy, 2008). Therefore, it would be beneficial to conduct a study to evaluate the effect of light emitting diode (LED) versus halogen photoplymerization on shear (push-out) bond strength of three types of resincomposites.

\section{MATERIALS AND METHODS}

\section{Selection of teeth and Grouping of specimens:}

A total of sixty freshly extracted for periodontal reasons human caries free permanent molars were selected for this study. The molars were collected from patients between 40-60 years old. Teeth were then stored in distilled water ${ }^{*}$ at room temperature till use. The selected teeth were randomly divided into two main groups 30 teeth each according to the used light-curing unit either light-emitting diodecuring unit (LED) (PM-LED02; China) or quartz tungsten halogen (QTH) (Cromalux-E ; Germany) curing unit. Each main group of teeth was further subdivided into three subgroups 10 teeth each, according to the type of resin composite: either hybrid resin-composite (Filtek Z250), nano-filled resin-composite (Filtek Supreme XT), or silorane based resin-composite (Filtek P90).

\section{Preparation of push-out test specimens:}

Acrylic resin blocks were formed by embedding teeth in cylindrical plastic molds containing acrylic resin (Acrostone dental factory, Egypt) till the crown level, with the occlusal surfaces facing outside in the center of the mold. A grinding-drilling machine (BV20B-L, Automatic Feed Bench Lathe, Bengbu, China) was used for abrading occlusal enamel under water coolant using a metal bar till flat dentin surfaces were exposed. A driller $3 \mathrm{~mm}$ in diameter was used to drill a standardized hole in the center of each tooth. A dentin disc $2 \mathrm{~mm}$ in thickness was cut from each tooth using a metal disc.

To each resin-composite used as in table (1), dentin surfaces were treated in accordance with manufacturer's instructions. After conditioning and adhesive systems application, each type of resin-composite was bulk inserted into the dentin disc specimen. LED or QTH was used for curing each type of resin-composite (hybrid, nano-filled or silorane-based) for 40 seconds. Then the specimens were stored in distilled water at room temperature for 24 hours prior to push-out testing.

Each specimen was fitted in a specially constructed metal jig and then was tested for

\footnotetext{
* CID solvent chemical industries development; Giza ARE.
} 
TABLE (1) The materials used in the current study.

\begin{tabular}{|c|c|c|}
\hline Materials & Composition & Lot \\
\hline Filtek Z250 & Hybrid methacrylates-based resin-composite & 1370 \\
\hline $\begin{array}{c}\text { Filtek } \\
\text { Supreme XT }\end{array}$ & Nano-filled methacrylates-based resin-composite & 3910 \\
\hline Filtek P90 & $\begin{array}{l}\text { Silorane-based resin-composite } \\
\text { Resin matrix; Silorane (3,4 Epoxycyclohexylethyl cyclo- polymethylsiloxane, bis-3,4- } \\
\text { epoxycyclohexylethyl-phenlmethylsilane ) }\end{array}$ & 4762 \\
\hline $\begin{array}{l}\text { Adper single bond } \\
2 \text { adhesive }\end{array}$ & $\begin{array}{l}\text { Etch \& rinse (2-step procedure) } \\
\text { Bond matrix: Bis-GMA, HEMA,Water, dimethacrylates, Ethanol methacrylates, } \\
\text { Functional copolymer of polyacrylic \& polyitaconic acid and silica photoinitiator }\end{array}$ & $\begin{array}{r}7523 \\
51202\end{array}$ \\
\hline $\begin{array}{c}\text { Filtek P90 system } \\
\text { adhesive }\end{array}$ & $\begin{array}{l}\text { (2-step) self-etch adhesive } \\
\text { Bond matrix: Hydrophobic dimeth-acrylate, phosphorylated methacrylate, silane-treated } \\
\text { silica filler, TEGDMA, initiators and stabilizers }\end{array}$ & $\begin{array}{l}4763 \mathrm{P} \\
4763 \mathrm{~B}\end{array}$ \\
\hline
\end{tabular}

Abbreviations: Bis-GMA, bisphenyl Glycidylmethacrylate; HEMA, hydroxethyl methacrylate; TEGDMA, triethlene glycol dimethacrylate.

shear bond strength using the universal testing machine (Nexygen-MT; Lloyd Instruments) at a crosshead speed of $0.5 \mathrm{~mm} / \mathrm{min}$. the fracture loads were obtained in Newton $(\mathrm{N})$. To express the shear strength in MPa the following formula was used:

$$
\begin{aligned}
& \tau=\mathbf{P} / \pi \mathbf{d h} \\
& \text { Where; } \boldsymbol{\tau}=\text { shear strength } \\
& P=\text { load at failure } \\
& \pi=3.14, d=\text { diameter of punch } \\
& h=\text { height of sample }
\end{aligned}
$$

Fracture mode of one representative specimen of each subgroup was examined using environmental scanning electron microscope at $800 \mathrm{X}$ magnification (Philips, model XL30, Neither land). Statistical analysis was performed using ANOVA and Newman-Keuls (NK) multiple comparison tests.

\section{RESULTS}

Table (2) and figure (1) show punch-out shear bond strength results (Mean \pm SD) of the tested resin based restorative materials with both curing systems.
TABLE (2) Punch-out shear bond strength results $(\mathrm{Mean} \pm \mathrm{SD})$ of the tested resin based composites with both curing systems

\begin{tabular}{|c|c|c|c|c|}
\hline \multirow{2}{*}{ Curing system } & \multicolumn{2}{|c|}{ With halogen } & \multicolumn{2}{c|}{$\begin{array}{c}\text { With light } \\
\text { emitting diode }\end{array}$} \\
\cline { 2 - 5 } Composite & Mean & \pm SD & Mean & \pm SD \\
\hline Silorane composite & 22.47 & \pm 0.6883 & 25.50 & \pm 1.364 \\
\hline Nano-composite & 17.35 & \pm 1.208 & 19.20 & \pm 0.8593 \\
\hline Hybrid composite & 15.74 & \pm 1.041 & 17.53 & \pm 0.8838 \\
\hline
\end{tabular}

HAL; Halogen curing system LED; Light emitting diode curing system

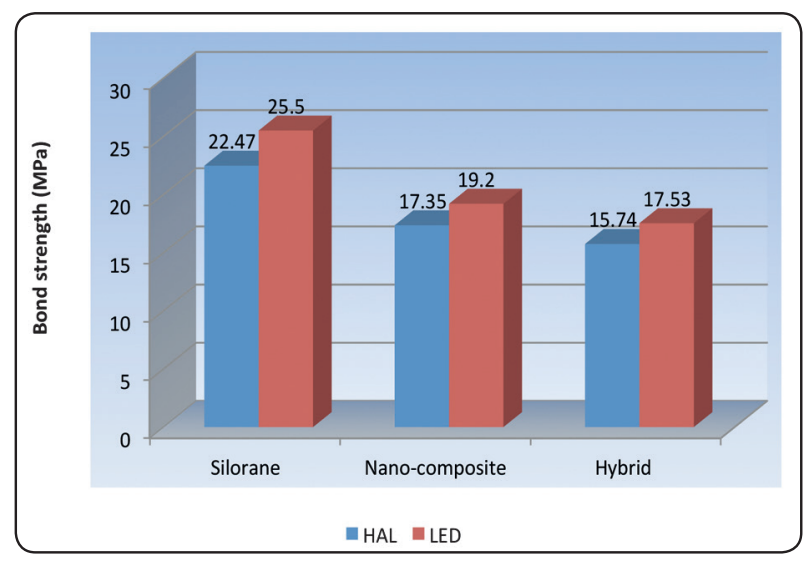

Fig. (1) A bar chart of punch-out shear bond strength mean values of the tested resin based composites with both curing systems. 
Silorane composite cured with light emitting diode curing unit recorded the highest mean shear bond strength value while Hybrid composite cured with halogen curing unit recorded the lowest mean shear bond strength value. All the specimens cured by light emitting diode demonstrated higher shear bond strength than those cured by halogen. Although, there were no statistically significant differences between the two LCUs except for Nanocomposite that showed a significant difference. With both curing units Silorane composite group was statistically significant higher than Nanocomposite and Hybrid composite groups. Nanocomposite was statistically non-significant higher than Hybrid composite group.

Regarding fracture mode analysis as shown in figure (2), an adhesive mode of failure was observed in hybrid resin composite group cured with halogen curing system, nano-filled resin composite group cured with light emitting diode curing system and both groups of silorane based resin composite. While cohesive mode of failure was observed in both hybrid resin composite group cured with light emitting diode curing system and nano-filled resin composite group cured with halogen curing system as shown in figure (3).

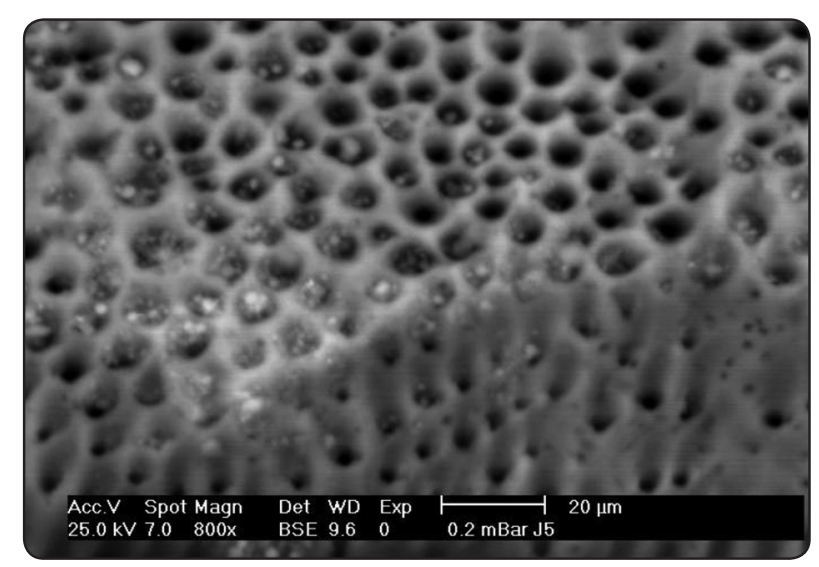

Fig. (2): An adhesive mode of failure

\section{DISCUSSION}

Dental resins cured with blue light emitting diodes have a higher degree of polymerization and a more stable 3-dimensional structure than those cured with halogen lamps (Banerjee \& Sable, 2010). It is therefore important to evaluate and compare the shear bond strength of resin composites polymerized using the LED and QTH curing units.

The results of the present study in table (2) and figure (1) showed that all the specimens cured by LED demonstrated higher shear bond strength than those cured by QTH. Although, there were no statistically significant differences between the two light curing units (LCUs) except for nano-filled resin-composite that showed a significant difference. Nano-filled resin composite has the smallest filler particles. Since smaller filler particles scatter the light more than large filler particles. The higher the proportion of filler, the more difficult it is for the light to penetrate the composite (Mills et al, 1999). This was in agreement with findings observed by (Caughman et al, 1995), (Lopes et al, 2008) and (Ghullman \& El-Gazawi, 2009) who found greater attenuation and scattering of light by the submicron filler particles than other light cured resins, requiring more energy for adequate polymerization.

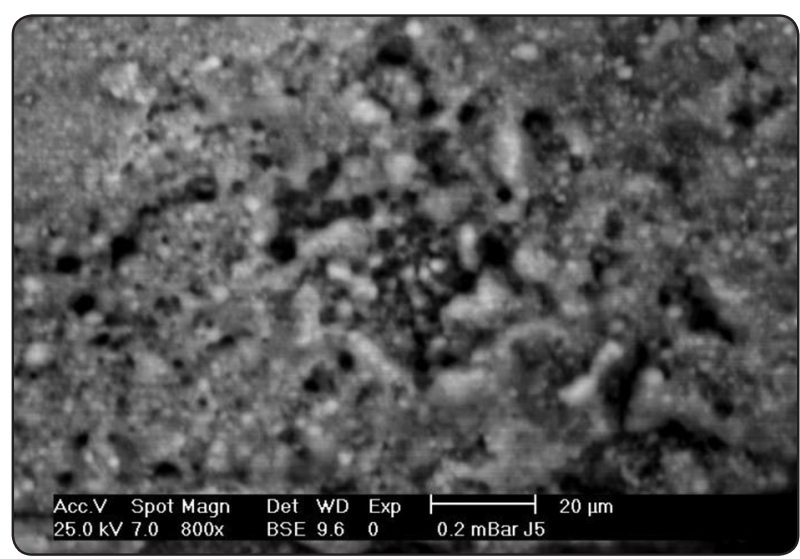

Fig. (3): A cohesive mode of failure 
Higher shear bond strength obtained with LED light curing unit can be attributed to that the emission peak of the LED LCU used in this study was ranged from $460 \mathrm{~nm}$ to $470 \mathrm{~nm}$, which is relatively close to the maximum absorption peak of CQ (468) while the emission peak of QTH LCU was ranged from $400 \mathrm{~nm}$ to $500 \mathrm{~nm}$. This means that the photons emitted from LED LCU have higher probability of being absorbed by CQ than that those emitted by halogen LCU as reported by Kim et al, 2005. In other words, in halogen light, because of the selective absorption characteristics of photo-initiator camphorquinone, $98 \%$ of the radiation does not contribute to polymerization (Klocke et al, 2002). Therefore, LED produces an almost ideal bandwidth of the light that is required (Krishnaswamy \& Sunitha, 2007). Besides, that LED source producing the same irradiance as halogen source produces a significantly greater depth of cure than the halogen source.

This finding was in agreement with the findings of Dunn and Taloumis, 2002, Bishara, 2003, Loretto et al, 2004, Banerjee and Sable, 2010, Nicoló et al, 2010 and Retamoso et al, 2010. While it was in disagreement with findings observed by D'Alpino et al, 2006 who found that significantly lower values were observed when the LED light was used to polymerize DBA compared to QTH and plasma arc (PAC) lights. Their reasonable explanation for the poorer results for the LED light is related to its narrow radiation spectrum. It is possible that the DBA contains photoinitiators other than camphorquinone which absorb light at lower wavelengths. Some initiators can be activated with the broad range QTH and PAC light sources but not with narrow range LED lights.

The present study showed that with both QTH and LED curing systems, silorane based resincomposite recorded statistically significant highest punch-out shear bond strength mean value followed by nano-filled resin-composite. Meanwhile hybrid resin-composite recorded the lowest punch-out shear bond strength mean value, while nano-filled resin composites were statistically non-significant higher than hybrid resin-composite groups.

Silorane System Adhesive Bond is based on methacrylate chemistry. It contains a unique hydrophobic bifunctional monomer in order to match the hydrophobic silorane resin. Other components include acidic monomers that initiate the ring-opening cationic cure of Filtek Silorane restorative, thus providing chemical bonding to Filtek Silorane (Fahmy, 2008). The Silorane Adhesive showed a very high degree of conversion (DC) within the hybrid layer (HL) that could significantly contribute to the formation of a stable adhesive interface (Navarra et al, 2009). In addition to the acid-base resistant zone in dentin is located adjacent to the hybrid layer in self-etch adhesive systems and may also influence the bond durability as it is more chemically and mechanically stable than normal dentin (Roeder et al, 2011).

The result of the present study was in agreement with Tagami et al,2010 who reported that, regarding the adhesive with self-etch primer, comparatively more stable bond durability was confirmed than that with the adhesive system using the more aggressive acid etching. It is also in agreement with Van Meerbeek et al, 2010 and Roeder et al, 2011 who suggested that, when bonding to dentin, a mild self-etch approach is superior, as it involves (like with glass-ionomers) additional ionic bonding with residual hydroxyapatite (Hap). This additional primary chemical bonding definitely contributes to bond durability.

Available difference between methacrylates and oxiranes is that methacrylates are cured by radical intermediates and oxiranes polymerize via cationic intermediates (Weinmann et al, 2005). Whereas methacrylate photo- polymerizations involve the conversion of a carbon-carbon double bond into single bonds, the ring-opening reaction relies on 
the opening of a cyclic structure to facilitate intermonomer bonding and crosslinking (Bowman et $\boldsymbol{a l}, \mathbf{2 0 1 0}$ ). The differences in composition and the conversion mechanism of silorane monomer and the tested MBCs may contribute to the findings of this study.

With methacrylate based composites (MBCs), polymerization shrinkage and diffusion of moisture through the resin component lead to the initiation and propagation of microcracks in the resin matrix. In contrast the polymerization shrinkage of Filtek Silorane was lower $(<1 \%)$ than the MBCS (1.9$3.5 \%)$. In other words, the MBCs could be more affected than Filtek Silorane with respect to the immersion in the storage solutions (Yesilyurt et al, 2009). Besides, some authors reported that zirconia/silica fillers were more susceptible to aqueous attack. While composites containing quartz fillers were shown to be less susceptible to aqueous attack (Ali et al, 2010).

These findings were in agreement with that the silorane technology provides restorative composites with the lowest polymerization shrinkage and stress as reported by Weinmann et al 2005. They were also in agreement with Allen et al, 2006 who found that the total volumetric polymerization shrinkage was reported as $0.99 \%$ for the siloranes, which was half as great as commercially available composites.

Although, the analyzed hybrid and nano-filled resin composites were used with the same adhesive system and had the same chemical composition but the bond strength values revealed that nanocomposite had higher mean shear bond strength than that of hybrid resin composite although it was not significant. This could be due to the use of nanotechnology in nanocomposite.

Increased filler content has been associated with lower volumetric shrinkage, as it reduces the volume of organic matrix present in the material. However, a negative effect on composite degree of conversion attributed to the filler have been reported, caused by the mobility restrictions imposed on the reactive species and by light scattering (Gonçalves et al, 2010). Since, increased filler content has a negative effect on composite degree of conversion this may be explained as a contributing factor for why nanocomposite showed higher shear bond strength than hybrid resin-composite as the higher degree of conversion, lead to higher final shrinkage, which contributes to producing higher stresses (Braga and Ferracane, 2004).

This finding of higher shear bond strength of nanocomposite than hybrid composite was in agreement with the findings that were observed by Khatri et al, 2007, Seghal et al, 2008, Ghullman \& EL-Gazawi, 2009 and Bowman et al, 2010.

Based on that concluded by Hara et al, 2001 who reported that in the SBS test, the variation of cross-head speed may influence the bond strength values and the fracture pattern obtained. Cross-head speeds of 0.50 and $0.75 \mathrm{~mm} / \mathrm{min}$ result in more adhesive failures. In this study the cross-head speed was $0.5 \mathrm{~mm} / \mathrm{min}$.

In the current study, the fracture modes were shown in figures (2\&3). An adhesive mode of failure was observed in hybrid resin composite group cured with halogen curing system, nano-filled resin composite group cured with light emitting diode curing system and both groups of silorane based resin composite. While cohesive mode of failure was observed in both hybrid resin composite group cured with light emitting diode curing system and nano-filled resin composite group cured with halogen curing system. These findings of mode of failure examination could be due to shrinkage forces which develop when composite is bonded to cavity walls. This resulting in stresses on the bond between composite and tooth structure. These forces are not uniformly distributed along the cavity walls, the bond strength between tooth and composite also varies along the bonded surface (Braga $\&$ Ferracane, 2004).

With MBCs, polymerization shrinkage and diffusion of moisture through the resin component 
lead to the initiation and propagation of microcracks in the resin matrix. In contrast the polymerization shrinkage of Filtek Silorane was lower $(<1 \%)$ than the MBCS (1.9-3.5\%). This mean that, Filtek Silorane could be less affected than the MBCs with respect to the immersion in the storage solutions (Yesilyurt et al, 2009). Besides, in the current study only a representative area of a representative specimen of each group was selected for the purpose of mode of failure examination.

The findings of this study were in agreement with Braga et al, 2010 and Roeder et al, 2011 who reported that cohesive failure is explained by the mechanics of the test and brittleness of the materials involved. While this was in disagreement with that found by Van Meerbeek et al, 2010, who reported that the higher the bond strength, the higher the rate of cohesive failure.

\section{CONCLUSION}

Within the limitations of this in-vitro study and based on the obtained results, the following Conclusions could be drawn:

(1) The light emitting diode is effective as halogen curing light to obtain resin-composite with shear bond strength of no significant difference.

(2) The silorane-based resin-composite restorative material is promising material regarding bonding efficiency to dentin.

\section{RECOMMENDATION}

It is advised to cure nano-filled resin composite with light emitting diode (LED) to obtain higher shear bond strength to dentin.

\section{REFERENCES}

- $\quad$ ADA Division of Science, in cooperation with the Journal of American Dental Association: Visible light curing. Journal of American Dental Association 2002; 133:1429-31.

- Ali A, El-Zawahry M and Souhail M: Evaluation of some properties of novel (low shrinkage) composite resin.
A thesis Submitted to the Faculty of Dental Medicine, AlAzhar University, Dental Bio-Materials Department in partial fulfillment of the requirements for Doctor of Philosophy Degree 2010: 1-149.

- Allen E, Brodine A, Burgess J, Cronin R, Donovan T and Summitt J: Annual review of selected dental literature: Report of the committee on scientific investigation of the American Academy of Restorative Dentistry. The Journal of Prosthetic Dentistry 2006; 96:174-99.

- Banerjee S and Sable R: A comparative evaluation of the shear bond strength of five different orthodontic bonding agents polymerized using halogen and LED curing lightsan in vitro investigation. Journal of Clinical and Diagnostic Research 2010; 4:2116-24.

- Bishara S: Evaluation of a new curing light on the shear bond strength of orthodontic brackets. Angle Orthodontist 2003; 73:431-5.

- Bowman C, Cramer N and Sansbury J: Recent advances and developments in composite dental restorative materials. Journal of Dental Research 2010; 90(4):402 -16.

- Braga R and Ferracane J: Alternatives in polymerization contraction stress management. Critical Reviews in Oral Biology and Medicine 2004; 15:176-84.

- Braga R, Meira J, Boaro L and Xavier T: Adhesion to tooth structure: A critical review of macro test methods. Dental Materials 2010; 26:38-49.

- Caughman W, Rueggeberg F and Curtis J: Clinical guidelines for photocuring restorative resins. Journal of American Dental association 1995; 126:1280-6.

- D’Alpino P, Wang L, Rueggeberg F, Svizero N, Pereira J, Pashley D and Carvalhog R: Bond strength of resin-based restorations polymerized with different light-curing sources. Journal of Adhesive Dentistry 2006; 8:293-8.

- Dunn W and Taloumis L: Polymerization of orthodontic resin cement with light-emitting diode curing units. American Journal of Orthodontics and Dentofacial Orthopedics $2002 ; 122: 236-41$

- $\quad$ Fahmy OMI: Bonding efficiency of a novel low shrinkage composite (silorane) to dentin; microshear and nanoleakage study. Egyptian Dental Journal 2008; 54:1417-34.

- Ghulman M and El-Gazawi S: Compressive and flexural strength in relation to shear bond strength of dental composites to tooth structure. Egyptian Dental Journal 2009; $55: 869-75$. 
- Gonçalves F, Kawano Y and Braga R: Contraction stress related to composite inorganic content. Dental Materials 2010; 26:704-9.

- Hahnel S, Henrich A, Rosentritt M, Handel G and Bürgers $\mathrm{R}$ : Influence of artificial ageing on surface properties and Streptococcus mutans adhesion to dental composite materials. Journal of Materials Science: Materials in Medicine 2010; 21:823-33.

- Hara A, Pimenta L and Rodrigues Jr A: Influence of crosshead speed on resin-dentin shear bond strength. Dental Materials 2001; 17:165-9.

- Khatri A, Nadlal B and Srilatha: Comparative evaluation of shear bond strength of conventional composite resin and nanocomposite resin to sandblasted primary anterior stainless steel crown. Journal of Indian Social Pedodontic Preventive Dentistry 2007; 25: 82-5.

- $\quad$ Kim S, Lee I, Cho B, Son H and Um C: Curing effectiveness of a light emitting diode on dentin bonding agents. Applied Biomaterials 2005; 77: 164-70.

- Klocke A, Korbmacher H, Huck L and Nieke B: Plasma arc curing lights for orthodontic bonding. American Journal of Orthodontics and Dentofacial Orthopedics 2002; 122:643-8.

- Krishnaswamy NR and Sunitha C: Light-emitting diode vs. halogen light curing of orthodontic brackets: A 15-month clinical study of bond failures. American Journal of Orthodontic and Dentofacial Orthopedics 2007; 132:518-23.

- Lopes L, Franco E, Pereira J and Mondelli R: Effect of light-curing units and activation modes on polymerization shrinkage and shrinkage stress of composite resins. Journal of Applied Oral Science 2008; 18:35-42.

- $\quad$ Loretto S, Braz R, LYRA A and Lopes L: Influence of photopolymerization light source on enamel shear bond strength after bleaching. Brazilian Dental Journal 2004; $15: 133-7$.
- Mills R, Jandt K and Ashworth S: Dental composites depth of cure with halogen and blue light emitting diode technology. British Dental Journal 1999; 186:388-91.

- $\quad$ Navarra C, Cadenaro M, Armstrong S, Jessop J, Antoniolli F, Sergo V, Di Lenarda R and Breschi L: Degree of conversion of Filtek Silorane Adhesive System and Clearfil SE bond within the hybrid and adhesive layer: An in situ Raman analysis. Dental Materials 2009; 25:1178-85.

- Nicoló R, Araujo M, Alves L, Souza R and Rocha D: Shear bond strength of orthodontic brackets bonded using halogen/light-emitting diode at different debond times. Brazilian Oral Research 2010; 24:64-9.

- Retamoso L, Onofre N, Hann L and Marchioro E: Effect of light-curing units in shear bond strength of metallic brackets: an in vitro study. Journal of Applied Oral Science 2010; 18:68-74.

- $\quad$ Roeder L, Pereira PNR, Yamamoto T, Ilie N, Armstrong S and Ferracane J: Spotlight on bond strength testing-Unraveling the complexities. Dental materials 2011; 27:1197-03.

- Sehgal A, Rao Y, Joshua M and Lakshmi L: Evaluation of the effects of the oxygen-inhibited layer on shear bond strength of two resin composites. Journal of Conservative Dentistry 2008; 11:159-61.

- Tagami J, Nikaido T, Nakajima M and Shimada Y: Relationship between bond strength tests and other in vitro phenomena. Dental Materials 2010; 26:94-9.

- Van Meerbeek B, Peumans M, Poitevin A, Mine A, Van Ende A, Neves A and De Munck J: Relationship between bond-strength tests and clinical outcomes. Dental Materials 2010; 26:100-21.

- Weinmann W, Thalacker C and Guggenberger R: Siloranes in dental composites. Dental Materials 2005; 21:68-74.

- $\quad$ Yesilyurt C, Yoldas O, Al Tintas S and Kusgoz A: Effects of food-simulating liquids on the mechanical properties of a silorane-based dental composite. Dental Materials 2009; 28:362-7. 